Originally published as:

Anette Siedler, Annette Mankertz, Fabian Feil, Gabriele Ahlemeyer, Angelika Hornig, Markus Kirchner, Konrad Beyrer, Johannes Dreesman, Sibylle Scharkus, Anne Marcic, Sabine Reiter, Dorothea Matysiak-Klose, Sabine Santibanez, Gérard Krause and Ole Wichmann

Closer to the Goal: Efforts in Measles Elimination in Germany 2010

(2011) Journal of Infectious Diseases, 204 (supplement1), pp. 373-380.

DOI: 10.1093/infdis/jir068

This is a pre-copy-editing, author-produced PDF of an article accepted for publication in The Journal of Infectious Diseases following peer review. The definitive publisher-authenticated version is available online at: http://jid.oxfordjournals.org/content/204/suppl 1/S373.full 


\title{
Closer to the Goal: Efforts in Measles Elimination in Germany 2010
}

Anette Siedler ${ }^{1}$, Annette Mankertz ${ }^{2}$, Fabian Feil ${ }^{4}$, Gabriele Ahlemeyer ${ }^{6}$, Angelika Hornig $^{7}$, Markus Kirchner $^{5}$, Konrad Beyrer ${ }^{5}$, Johannes Dreesman ${ }^{5}$, Sibylle Scharkus ${ }^{8}$, Anne Marcic ${ }^{9}$, Sabine Reiter ${ }^{1}$, Dorothea Matysiak-Klose ${ }^{1}$, Sabine Santibanez ${ }^{2}$, Gérard Krause ${ }^{3}$ and Ole Wichmann ${ }^{1}$

${ }^{1}$ Department for Infectious Disease Epidemiology, Immunization Unit

${ }^{2}$ National Reference Laboratory Measles, Mumps, Rubella

${ }^{3}$ Department for Infectious Disease Epidemiology, Robert Koch Institute, Berlin

${ }^{4}$ Ministry of Social Affairs, Women's and Family Issues, Health, and Integration of Lower Saxony

${ }^{5}$ Governmental Institute of Public Health of Lower Saxony, Hannover

${ }^{6}$ State Institute of Health and Labour of North-Rhine Westfalia, Duesseldorf

${ }^{7}$ Ministry of Labor, Social Affairs, Health, Family, and Women of Rhineland-Palatinate, Mainz

${ }^{8}$ Department for Public Health, Medical, Pharmaceutical and Social Affairs and Hospital Funding,

District Government, Koeln

${ }^{9}$ Ministry of Labor, Social Affairs and Health of Schleswig-Holstein, Kiel, Germany

\begin{abstract}
Increasing 2-dose vaccination coverage has led to an interruption of endemic measles virus circulation in Germany. However, outbreaks after virus importation still occur and contribute to international transmission chains. Between 2003 and 2009, annual measles incidence ranged between 0.2 and 2.8 per 100,000 population. Immunization gaps have been identified especially in secondary-school students and young adults, which is also reflected by a shift in age distribution of reported measles cases toward older age groups. Stronger political commitment and standardized guidelines for outbreak containment were put in place in Germany in the past years, but the last step toward measles elimination cannot be made until the number of susceptible individuals has been further reduced. In addition to routine childhood vaccination, supplementary immunization activities are needed targeting school students and young adults to close critical immunization gaps. Intensification of public awareness and sound information on vaccinations are necessary to convince skeptics and remind the forgetful.
\end{abstract}

Germany committed itself to attain the World Health Organization (WHO) goal of measles elimination in the European region and implemented a national intervention program against measles, mumps and rubella (MMR) in 1999 [1]. As of 2010, WHO performance indicators for measles surveillance [2] were mainly achieved, and Germany has experienced a declining trend in measles activity during recent years. However, elimination targets have not been fully reached in Germany yet: Regionally limited outbreaks occurred almost every year and contributed to long-lasting transmission chains in Europe [3], and 95\% vaccination coverage with 2 doses of measles-containing vaccine (MCV) has not been reached in children.

Germany consists of 16 federal states with a total of $~ 82$ million inhabitants. Measures for disease control, including implementation of vaccination recommendations and activities and monitoring of vaccination coverage, is the responsibility of the individual states. The German Standing Committee on Vaccination (STIKO) provides recommendations, which are endorsed by the state health authorities. Vaccinations are not obligatory and also not required for attending public schools, kindergartens, or the like. General practitioners and pediatricians usually administer the vaccines, 
which are financed by the statutory health insurance system. There are substantial regional differences in population densities and in various aspects of health care. In particular with regard to vaccination coverage, differences still exist between states that belonged to West Germany before reunification in 1990 (old federal states [OFSs]) and those that belonged to the German Democratic Republic (new federal states [NFSs]) [4, 5]. Our objective was to characterize the measles epidemiology in Germany by describing the surveillance infrastructure and epidemiologic trends and by highlighting some examples of special measures that state health authorities have initiated together with federal public health institutions to accelerate measles elimination in Germany.

\section{Measles epidemiology}

Since 2001, both clinically suspected and laboratory confirmed measles cases have to be reported to local health departments in Germany according to the Communicable Diseases Law Reform Act (IfSG). The local health departments are in charge of conducting control measures and electronically report cases via the state health department to the Robert Koch Institute (RKI), the federal institution for disease prevention and control [6]. The WHO performance indicators for measles surveillance in terms of timeliness and completeness of reporting and adequacy of investigation are achieved by the system [2]. At least $90 \%$ of case reports have complete information on age, sex, date of disease onset, vaccination status, date of last vaccination, and travel history. Underreporting of measles cases by the national surveillance system is likely, but its degree is unknown. Between 2007 and 2009, $\sim 80 \%$ of reported measles cases without epidemiologic link were laboratory confirmed, either serologically or with polymerase chain reaction.

An annual incidence of $<0.1$ cases per 100,000 population, $80 \%$ of outbreaks with $<10$ cases, and no endemic circulation of imported measles virus (MV) strains for $>12$ months are WHO indicators and targets for measles elimination [2]. Whereas annual incidences were $>5$ cases per 100,000 population in 2001 and 2002 in Germany, this number dropped to 1 per 100,000 since 2003 with 2 exceptions: first in 2004, when the lowest measles incidence was reached with $(0.2 / 100,000)$ and second in 2006, when a large outbreak with 1749 reported cases occurred in North-Rhine Westphalia, belonging to the OFS, increasing the national incidence to $2.8 / 100,000$. Annual incidences in the 16 federal states varied considerably $(0-18 / 100,000)$ and were on average lower in the NFSs (mean incidence 2003$2009, .14 / 100,000)$ than in the OFSs $(1.22 / 100,000)$ (Table 1). The largest outbreak observed in the NFSs since 2001 included only 14 cases. In the OFSs, outbreaks with >20 cases have occurred every year, but the size and duration of these outbreaks have decreased during the past 9 years (Figure 1).

As in other countries in the preelimination phase, an increasing proportion of cases in older age groups and an increase in age-specific incidences in persons 10-39 years of age have been observed in Germany since 2006 (Figure 2). Whereas the incidence generally decreased among children $<10$ years of age, it remained high in infants (incidence range in infants, 2.1-5.7/100,000 in 2003-2005 vs $3.5-7.3 / 100,000$ in 2007-2009).

\section{Molecular epidemiology}

Genetic characterization of circulating MV has been established at the National Reference Centre for Measles, Mumps, and Rubella (NRC-MMR) at the RKI in the mid-1990s. The indigenous European genotypes C2 and D6 (MVi/Kempten.DEU/23.00, MVi/Berlin.DEU/47.00) were predominant in Germany until 2000 and then rapidly replaced by D7 (MVi/Mainz.DEU/06.00) from 2000 to 2002 [7]. Transmission of indigenous MV variants was tapering off in 2003, and has been interrupted in 2004 [8]. A variety of MV strains was detected from 2005 onward (Table 2). Most of them were identical to MV circulating in other European countries or endemic in Asia and Africa, indicating that all of these viruses were imported. They led to limited outbreaks in Germany and contributed to international

In 2006, the above mentioned outbreak in North Rhine-Westphalia was caused by a MV genotype D6 (MVs/Moenchengladbach.DEU/19.06), which was unrelated to the D6 virus detected in a Bavarian outbreak in 2005, but showed identity to the D6 virus (MVs/Kyiv.UKR/03.06/1) causing a large outbreak in the Ukraine in 2005-2006. Therefore, importation from Eastern Europe was likely. 
The MV variant D5-Lucerne was observed in Lower Bavaria in 2007 and a year later in Upper Bavaria, Baden-Wuerttemberg, and in smaller outbreaks all over Germany (Table 2) [15], probably owing to multiple importations from Switzerland, where a large outbreak was observed from 2006 to 2009 ( $>4400$ cases) [14]. D5 transmission was no longer detected in Germany in 2009, when various D4 variants were found instead, closely related to D4-Enfield; an imported D4 variant from the United Kingdom was associated with an outbreak in Hamburg and Lower Saxony (Table 2) and was subsequently exported to Bulgaria, where it started to circulate mainly within the Roma community [17]. In 2009, a second D4 variant was detected in North Rhine-Westphalia and a third D4 strain in Baden-Wurttemberg (Table 2), suggesting multiple importations from outside the country rather than spread within Germany.

Although MV genotypes and variants such as D4-Enfield and D5-Lucerne did not become endemic in Germany, it is evident that endemic transmission of these viruses did occur in the WHO-EURO zone [Mankertz et al, in this issue]. Molecular surveillance supports the fact that endemic MV circulation has been interrupted in Germany since 2003, but the number of susceptible individuals is still large enough to allow measles outbreaks to occur after virus importation.

\section{Measles vaccination coverage}

Childhood measles vaccination with 1 vaccine dose was recommended in the OFSs since 1973, with voluntary application, and it was mandatory for school and kindergarten entry in the NFSs since 1970 with 1 vaccine dose and since 1986 with 2 vaccine doses, until reunification in 1990. After reunification of Germany in 1991, the STIKO recommended a 2-dose MCV schedule, with the first dose administered to children 1 year of age and the second to 4-6-year-olds. In 2001, the recommended ages for the first and second doses were changed to 11-14 months and 15-23 months, respectively, to provide an early second chance to gain immunity.

Vaccination coverage in Germany is routinely assessed at school entry, normally at the age of 6 years, and has increased in recent years (Figure 3). The increase in vaccine uptake was most prominent for the second vaccine dose in 2001-2005, which correlated with the above-described change in the target age group. For children entering school in 2008, coverage with $1 \mathrm{MCV}$ dose was $96 \%$. Twodose coverage was $89 \%$, still below the critical $95 \%$ coverage recommended for elimination [2, 19]. Coverage was lower in the OFSs than in the NFSs (1 dose, $95.6 \%$ vs $97.8 \%$; 2 doses $88.6 \%$ vs $92.1 \%$ ). The regional differences in coverage are likely to be a consequence of historically formed attitudes toward vaccination, and differences in engagement of the local public health service with regard to supplementary immunization activities (SIAs) in the different states. The denominator for calculating vaccination coverage is based on the number of students presenting their vaccination records at the medical school entry examination $(\sim 90 \%)$. The true coverage is therefore likely to be lower than presented above, assuming that those students who present their records are more likely to be vaccinated [11].

Outbreak investigations revealed that the main reasons for not being immunized were lack of awareness or rejection because of the perception of measles as a mild disease, the fear of vaccinerelated adverse events, and false understanding of contraindications [12, 16]. Besides better information and increased public awareness about measles and the benefits of vaccination, reminder and recall systems would be beneficial to both physicians and patients, to check and close immunization gaps whenever possible [20].

Philosophical beliefs in Germany and German -speaking areas of other European countries are associated with limited compliance with existing vaccination recommendations [21]. Several largescale outbreaks occurred in recent years in private anthroposophic kindergartens or schools, where coverage is usually low $[15,18]$. Anthroposophic physicians do not oppose immunization in general, but they prefer vaccinations based on an individual indication and at older age than recommended as they believe it might be favorable for a child's development to undergo natural infection [22, 23]. According to data from the representative German Health Interview and Examination Survey for Children and Adolescents (KIGGS) in 2003-2006, measles vaccination coverage was especially low in children with parents reporting general reservations against vaccinations, and also in foreign-born migrants, who had a 3-fold increased odd of being unvaccinated [24]. Unfortunately, data on health behavior or vaccination coverage in migrants or ethnic minorities are rare in Germany. The fact that 
outbreaks started in unvaccinated persons of ethnic minorities in Hessen in 2004 and Hamburg in 2009 (local health department, personal communication) demonstrated that more attention must be paid to persons who otherwise would not seek health prevention measures on their own.

\section{A state vaccination campaign 2007-2008}

In the biggest outbreak in recent years, $>1700$ measles cases were recorded in North RhineWestphalia in 2006, most of them unvaccinated students 9-18 years of age. Because data on vaccination coverage exist only from school entry examinations, little was known about the vaccination status of children $>6$ years. But according to data from the above mentioned KIGGS, the average 2dose MCV vaccination coverage was $77.5 \%$ among children aged $14-17$ years. In the light of these survey results and the 2006outbreak, the North Rhine-Westphalia State Ministry of Labor, Health and Social Affairs decided to carry out a vaccination campaign in 2007, involving all 54 local health departments and various other partners. Its purpose was to identify and close immunization gaps by offering voluntary vaccination at schools. However, not all local health departments contributed to this SIA, owing to varying levels of staffing and organization. The state vaccination campaign took place from November 2007 to June 2008 and focused on students 10-21 years of age. Participating local health departments received a set of information materials and financial support for the implementation of the campaign. The state ministry established email and telephone hotlines for professional health staff and the public. Local health departments checked the vaccination records and vaccinated children at schools either by themselves or with support of the Regional Association of Physicians, complementary to the usual vaccination through family physicians. The status of MMR vaccinations, and other vaccinations if possible, was recorded anonymously.

Of the 54 state municipalities, 51 participated in the SIA. According to the state school list, 2.8 million students attended secondary schools in 2008 . The evaluation included 264,634 persons aged $10-21$ years with complete data sets submitted by 51 municipalities; this corresponded to $9.4 \%$ of all students of that age group in the state. Of the 264,634 school students analyzed, 247,439 (93.5\%) had received $\geq 1 \mathrm{MCV}$ dose, and 17,195 (6\%) were unvaccinated. Vaccination coverage with $2 \mathrm{MCV}$ doses varied from $26.9 \%$ to $91.0 \%$ by municipality, with an average of $80.3 \%$. The percentage of students that had not received any vaccination against measles ranged from . $3 \%$ to $28.9 \%$ per municipality. No difference was found between male and female students. The vaccination status was best for the youngest age group (88\%) and dropped significantly with increasing age to $56 \%$ at 21 years (for $2 \mathrm{MCV}$ doses, $P<.05$ ) (Table 3 ). In total, almost 8000 MMR vaccine doses were administered at schools during the SIA, covering around $3 \%$ of the target group. Parents of children with incomplete vaccination status often preferred to have the vaccination done by their family physician or pediatrician, which was the case for $\sim 60 \%$ of students for whom vaccinations were recommended during the campaign but not completed at school.

For the first time in recent years, a state-wide vaccination campaign was conducted by a federal state in Germany and assessed measles vaccination coverage in students 10-21 years of age. The campaign made a major contribution to improving the vaccination situation in North Rhine-Westphalia, although it did not meet the target. It clearly confirmed that older students especially have considerable deficits in their vaccination status. It also showed that students at specific types of schools (vocational schools, extended elementary schools) benefit most when vaccinations are offered at school, because the lowest vaccination coverage was found in these populations. The results show clearly that immunization of older adolescents and young adults is urgently warranted. At many schools, only a small proportion of students submitted their vaccination record, and it can be assumed that the vaccination status of students without vaccination records is even worse. In future SIAs, persons who not present their records should receive the same offers and reminders as the unvaccinated. The vaccination campaign of 2007-2008 showed that closing immunization gaps is most effective if offering information and vaccination services in schools. However, these schoolbased programs must be prepared and accompanied by targeted information campaigns to improve parents' attitudes toward such activities. Because of the observed age shift in measles cases and detected immunization gaps in young adults, STIKO decided in 2010 to recommend measles vaccination for unvaccinated adults born after 1970 . 


\section{Measles case management}

Based on the If SG, local health departments may forbid persons with suspected or confirmed measles or their susceptible household contacts to attend or work in community facilities, such as schools or kindergartens. The large 2006 outbreak in North Rhine-Westphalia led to a debate in Germany on how to manage measles cases, especially among school students which has resulted in special guidelines for the public health service in the federal state of Lower Saxony [25]. Local health departments are technically supported in their measles control by the Governmental Institute of Public Health of Lower Saxony, which in turn cooperates with RKI and the NRC-MMR. The guidelines consist of 5 key elements:

1. Intensive follow-up of the index case: The most important element is a consistent early intervention at the occurrence of the first measles case to contain the spread of infection. This includes the search for the source of infection and the investigation of contact persons including their vaccination status and attendance at community facilities.

2. Laboratory confirmation of diagnosis: For reliable surveillance, $\geq 80 \%$ of measles cases should be confirmed by laboratory diagnostics [2]. Confirmation of the diagnosis is also important for other measures of case management, such as isolation. Local health departments initiate and finance laboratory investigations if adequate testing was not already initiated by the consulted physician.

3. Dissemination of information: Patients, their household members, staff and attendees of community facilities, physicians, laboratories, hospitals, and the media are being informed about the existing legal obligations and the purpose of the measures. Information material and letter templates are attached to the guidelines to ensure consistent and easily available information.

4. Vaccination: It is necessary to clarify whether susceptible individuals were in close contact with the case and whether postexposure vaccination is still an option. If so, the public health service of Lower Saxony will verify the actual vaccination status and actively offer vaccinations.

5. Isolation: Persons with suspected or confirmed measles, as well as their unprotected contacts are prohibited from attending or working in community facilities. Persons are regarded as unprotected as long as they cannot prove that they were vaccinated (children usually with 2 doses, adults with $\geq 1$ dose of MCV) or had measles previously. In the case of a vaccination within the first 3 days of exposure, isolation can be abandoned. The legal scope of the IfSG allowing such measures is specified in the guidelines but will need to be applied to only a few persons when vaccination coverage is high in the population.

Since the implementation of the guidelines in 2007, measles outbreaks were successfully limited and mitigated in Lower Saxony [26]. Nevertheless, MV infections still occurred, especially in certain population subgroups. The relatively high number of cases in 2009 was due to a supraregional outbreak in the federal state of Hamburg, adjoining Lower Saxony. Of the 72 cases reported 2009 in Lower Saxony, 43 were epidemiologically linked to cases in Hamburg. However, no secondary case arose from these cases in Lower Saxony. Intensified surveillance, according to the guidelines of the WHO, as well as consistent case management, as proposed in the Lower Saxon Guidelines, proved useful in preventing secondary cases after MV importation and spread to highly vulnerable populations.

\section{National Immunization Conference}

As demanded by the resolution from the first "Meeting of German-speaking Countries and Areas on Measles and Rubella Elimination," which was held with WHO/Europe in Berlin in May 2006, political commitment has changed over time [21, 27]. On the initiative of the federal state of RhinelandPalatinate the 16 German state health ministers have decided to hold National Immunization Conferences (NICs) every 2 years. Elimination of measles was a main topic of interest at the first 3day-long NIC in Mainz in March 2009. Some key recommendations to combat measles and to improve vaccination coverage emerged from presentations given by experts from the federal states, as well as from numerous posters and abstracts presented. Subsequent to the NIC, an overview of these recommendations was included in a "good practice manual," which will be published online and can be 
used as a support for public health authorities to eliminate measles. The recommendations are as follows:

1. Public health service activities: Public health services activities should focus mainly on schools, and include checking vaccination records combined either with vaccination on site or recommendations to obtain any missing vaccinations.

2. Recall systems in connection with school entry examination: The established activity for checking vaccination status at school entry was used in one federal state for the implementation of a recall system which showed promising results in closing immunization gaps.

3. Measles management with public health action plans: Detailed action plans were implemented in Lower Saxony (as described above) and in Bavaria. Key elements include the use of surveillance instruments and standardized procedures for the management of individual cases and outbreaks.

4. Public awareness campaigns: The general public needs to be reminded of the need for vaccinations by the provision of scientifically sound information. It is necessary to work against the uncertainty and confusion of parents and physicians in the field of vaccinations and particularly to counterbalance misinformation by aggressive antivaccination groups. Motivation tools could include cinema advertisements and campaigns using a variety of posters and flyers. Information materials should address the general public but also specific target groups.

5. Monitoring vaccination coverage: Monitoring coverage is crucial for improving immunization strategies. A new monitoring method in Germany uses billing data from the Association of Statutory Health Insurance Physicians. If this system can provide representative estimates, it could be an effective tool to collect vaccination coverage data across all age groups [28].

One important reason for the development of immunization gaps is the skepticism and lack of information among parts of the population. Alongside very small groups of steadfast vaccination opponents, who will not be swayed by reasonable arguments, there is a critical attitude toward vaccines in substantial parts of the medical community, particularly among those favoring anthroposophic medicine. Because these voices have a significant influence on parental opinion, dialogue was sought with these groups at the first NIC. Supported by intensive discussions in the years before, an influential group of anthroposophic doctors changed their point of view and announced on the conference that they will now be recommending measles vaccination [22].

Another important finding of the first NIC was that there are fundamentally good vaccination programs in Germany, but there are several responsible parties and decision makers, whose work is still not properly coordinated. As a result of the NIC, federal states decided on a national immunization plan that specifically incorporates the WHO target of measles elimination.

\section{Conclusion}

Disease and molecular surveillance data demonstrate that endemic MV circulation halted in Germany in 2003, but imported viruses continued to cause outbreaks with limited spread and duration especially in the western part of the country where vaccination coverage is lower. These outbreaks have contributed to sustained transmission chains in Europe. Lack of knowledge, poor acceptance of measles vaccination for philosophical reasons, and neglect are the main reasons for not being vaccinated in Germany. Successful measles elimination strategies have to include additional efforts to address these challenges and to overcome all possible obstacles to close immunization gaps.

Ministries of health at state and federal level have taken a number of measures to achieve measles elimination in Germany, which include state-wide SIAs with focus on schools, the introduction of measles management guidelines for local health authorities, the development of a national immunization plan, and the implementation of biyearly NICs. School-based SIAs should be conducted in all federal states. The extension of STIKO recommendation on measles vaccination to adults is aiming to close immunization gaps. Measles elimination has to be defined as a high-priority public health goal that needs stronger political commitment and coordinated measures by state, federal, and local authorities. The next NIC, scheduled to take place in February 2011 in Baden-Wurttemberg, will provide an opportunity to assess the progress and to exchange experiences with successful concepts working toward the goal of measles elimination in Germany and Europe. 


\section{Footnotes}

Potential conflicts of interest: none reported. 


\section{References}

1. Interventionsprogramm Masern-Mumps-Ro"teln, 1999.

http://www.rki.de/cln_178/nn_199620/DE/Content/Infekt/Impfen/Praevention/intervt, templateld5raw, property5publicationFile.pdf/intervt.pdf. Accessed 30 April 2010.

2. World Health Organization. Surveillance guidelines for measles, rubella and congenital rubella syndrome in the WHO European region. Copenhagen: WHO Regional Office for Europe, 2009. http://www. euro.who.int/document/e93035.pdf. Accessed 30 April 2010.

3. Muscat M, Bang H, Wohlfahrt J, Glismann S, Mølbak K. for the EUVAC.NET group. Measles in Europe: an epidemiological assessment. Lancet 2009; 373:383-9.

4. Hellenbrand W, Siedler A, Tischer A, et al. Progress toward measles elimination in Germany. J Infect Dis 2003; 187(Suppl 1):S208-16.

5. Robert Koch-Institut. 20 jahre nach dem Fall der Mauer: wie hat sich die Gesundheit in Deutschland entwickelt? Beitra"ge zur Gesundheitsberichterstattung des Bundes. Berlin: RKI, 2009; 169-75.

6. Faensen D, Claus H, Benzler J, et al. Surv Net@RKI: a multistate electronic reporting system for communicable diseases. Euro Surveill 2006; 11:100-3.

7. Santibanez S, Tischer A, Heider A, Siedler A, Hengel H. Rapid replacement of endemic measles virus genotypes. J Gen Virol 2002; 83:2699-708.

8. Kremer JR, Brown KE, Jin L, et al. High genetic diversity of measles virus, World Health

Organization European region, 2005-2006. Emerg Infect Dis 2008; 14:107-14.

9. Siedler A, Tischer A, Mankertz A, Santibanez S. Two outbreaks of measles in Germany, 2005. Euro Surveill 2006; 11:131-4.

10. Rota J, Lowe L, Rota $P$, et al. Identical genotype B3 sequences from measles patients in 4 countries, 2005. Emerg Infect Dis 2006; 12:1779-81.

11. Wichmann O, Hellenbrand W, Sagebiel D, et al. Large measles outbreak at a German public school, 2006. Pediatr Infect Dis J 2007; 26:782-6.

12. Wichmann O, Siedler A, Sagebiel D, et al. Further efforts needed to achieve measles elimination in Germany: results of an outbreak investigation. Bull World Health Organ 2009; 87:108-15.

13. Lernout T, Kissling E, Hutse V, Top G. Clusters of measles cases in Jewish orthodox communities in Antwerp, epidemiologically linked to the United Kingdom: a preliminary report. Euro Surveill 2007; 12:pii53308.

14. Richard JL, Masserey Spicher V. Large measles epidemic in Switzerland from 2006 to 2009: consequences for the elimination of measles in Europe. Euro Surveill 2009; 14:pii519443.

15. Pfaff G, Mezger B, Santibanez S, et al. Measles in south-west Germany imported from Switzerland: a preliminary outbreak description. Euro Surveill 2008; 13:pii58044.

16. Wadl M, Siedler A, Kra"mer M, et al. Why measles outbreaks still occur in the 21st century: yet another measles outbreak in a German federal state linked to low vaccination-coverage. ECDC Eurovaccine Scientific Conference on Vaccination \& Immunisation. Stockholm, 2009.

http://www.congressonline.eu/ecdc/pages/home. Accessed 4 May 2010.

17. Marinova L, Muscat M, Mihneva Z, Kojouharova M. An update on an ongoing measles outbreak in Bulgaria, April-November 2009. Euro Surveill 2009; 14:pii519442.

18. Ba"tzing-Feigenbaum J, Pruckner U, Beyer A, et al. Spotlight on measles 2010: preliminary report of an ongoing measles outbreak in a subpopulation with low vaccination coverage in Berlin, Germany, January-March 2010. Euro Surveill 2010; 15:pii519527.

19. Robert Koch-Institut. Impfquoten bei der Schuleingangsuntersuchung in Deutschland 2008.

Epidemiologisches Bull 2010; 16:137-40.

20. Oppermann H, Wahl G, Borrmann M, Fleischer J. Obligatory vaccination reporting in Saxony-

Anhalt: possibilities and limitations of establishing a computerized vaccination registry [in German].

Bundesgesundheitsblatt Gesundheitsforschung Gesundheitsschutz 2009; 52:1029-36.

21. World Health Organization. Measles and rubella in German-speaking countries/areas: current issues and challenges. Report of the meeting Berlin: WHO Regional Office for Europe and Robert Koch Institute, 2006. http://www.euro.who.int/en/what-we-do/health-topics/diseases-and-

conditions/measles-and-rubella/publications/pre-2009/measles-and-rubella-in-german-speakingcountriesareas-current-issuesand-challenges. Accessed 7 March 2011.

22. Schmidt-Troschke S. Impfungen aus Sicht der anthroposophischen Medizin. Public Health Forum 2009; 17:21-3.

23. Pfaff G. Reaching the hard to reach. ECDC Eurovaccine Scientific Conference on Vaccination \& Immunisation. Stockholm, 2009. http://www.congressonline.eu/ecdc/pages/home. Accessed 30 April 2010.

24. Poethko-Muller C, Ellert U, Kuhnert R, Neuhauser H, Schlaud M,

Schenk L. Vaccination coverage against measles in German-born and 
foreign-born children and identification of unvaccinated subgroups in Germany. Vaccine 2009; 27:2563-9.

25. Niedersa"chsisches Landesgesundheitsamt. Leitfaden fu"r das management von masernfa"llen. Hannover, 2007.

http://www.nlga.niedersachsen.de/index.php?navigation_id56636\&article_id519314\&_psmand520. Accessed 23 April 2010.

26. Robert Koch-Institut. Auf dem Weg zur Masernelimination bis zum Jahr 2010: Erfolge durch konsequentes Ausbruchsmanagement: Erfahrungsbericht aus Niedersachsen. Epidemiologisches Bull 2008; 07:53-5.

27. Robert Koch-Institut. Resolution des ersten Treffens der deutschsprachigen Staaten und Gebiete zur Eliminierung von Masern und Ro"teln, Berlin, 18-19. Mai 2006. Epidemiologisches Bull 2006; 22:171.

28. Reuss A, Feig M, Kappelmayer L, Eckmanns T, Poggensee G. Determination of vaccination coverage and disease incidence using statutory health insurance data [in German]. Das Gesundheitswesen 2010; 72:340-6. 


\section{Tables and Figures}

Table 1. Measles Cases and Incidences by Year and Region, Germany, 2001-2009

\begin{tabular}{ll} 
Year & \multicolumn{1}{c}{ Total no. of cases (cases $/ 100,000$} \\
population)
\end{tabular}

Cases $/ 100,000$ population (range)

Old federal states $(n=\quad$ New federal states $(n=$ Federal states with incidence $<0.1 / 100,000(n=$

11)

5)

16)

$\begin{array}{lll}8.6(0.4-18.0) & 0.7(0.1-1.4) & 0 \\ 6.7(0.4-13.0) & 0.4(0.2-0.9) & 0 \\ 1.1(0.1-5.1) & 0.2(0.05-0.4) & 3 \\ 0.2(0-0.3) & 0.1(0.04-0.1) & 7 \\ 1.1(0-4.3) & 0.2(0.04-0.4) & 3 \\ 3.3(0-9.7) & 0.2(0.02-0.4) & 2 \\ 0.8(0-1.7) & 0.04(0-0.1) & 6 \\ 1.3(0.2-3.6) & 0.2(0.04-0.6) & 2 \\ 0.8(0-12.0) & 0.1(0-0.2) & 6\end{array}$


Table 2. Major Measles Outbreaks in Germany Since 2005 With Dominant Measles Virus Genotype and Molecular or Epidemiologic Link

\begin{tabular}{|c|c|c|c|c|}
\hline Year and federal state ${ }^{a}$ & $\begin{array}{l}\text { Dominant MV } \\
\text { genotype }\end{array}$ & Accession no. of isolated virus* & Molecular or epidemiologic link* & Reference \\
\hline \multicolumn{5}{|l|}{2005} \\
\hline Hessen $(n=259)$ & D4 & MVs/Frankfurt.DEU/03.05 & $\begin{array}{l}\text { Molecular: Romania (MVs/Bucharest. } \\
\text { ROU/48.04/2)Epidemiologic: } \\
\text { Traveler from Romania }\end{array}$ & [9] \\
\hline Bavaria $(n=324)$ & D6 & MVs/Muenchen.DEU/17.05 & $\begin{array}{l}\text { Molecular: appeared sporadically in } \\
\text { Switzerland and in the Russian } \\
\text { Federation }\end{array}$ & [9] \\
\hline \multicolumn{5}{|l|}{2006} \\
\hline $\begin{array}{l}\text { Baden-Wuerttemberg } \\
(n=121)\end{array}$ & B3 & MVs/Stuttgart. DEU/04.06 & $\begin{array}{l}\text { Molecular: Nigeria and Kenya } \\
\text { (MVi/Nairobi.KEN/43.05) }\end{array}$ & {$[10]$} \\
\hline $\begin{array}{l}\text { North Rhine-Westphalia } \\
(n=1749)\end{array}$ & D6 & $\begin{array}{l}\text { MVs/Moenchengladbach. } \\
\text { DEU/19.06 }\end{array}$ & $\begin{array}{l}\text { Molecular: Ukraine } 2005-2006 \\
\text { (MVs/Kyiv.UKR/03.06/1) }\end{array}$ & {$[11,12]$} \\
\hline \multicolumn{5}{|l|}{2007} \\
\hline $\begin{array}{l}\text { North Rhine-Westphalia } \\
(n=251)\end{array}$ & D8 & MVs/Duesseldorf.DEU/11.07 & Molecular: South Asia & \\
\hline Bavaria $(n=105)$ & D4 & MVs/Muenchen.DEU/44.07 & $\begin{array}{l}\text { Molecular: United Kingdom } \\
\text { (MVs/Enfield.GBR/14.07), } \\
\text { later in Israel and Belgium }\end{array}$ & [13] \\
\hline Bavaria $(n=106)$ & D5 & MVs/Passau.DEU/11.07 & $\begin{array}{l}\text { Molecular: Switzerland } \\
\text { (MVs/Lucerne.CHE/46.06) }\end{array}$ & [14] \\
\hline \multicolumn{5}{|l|}{2008} \\
\hline $\begin{array}{l}\text { Baden-Wurttemberg } \\
(n=383)\end{array}$ & D5 & MVs/Freiburg.DEU/05.08 & $\begin{array}{l}\text { Molecular: Switzerland } \\
\text { (MVs/Lucerne.CHE/46.06) }\end{array}$ & [15] \\
\hline Bavaria $(n=306)$ & D5 & MVs/Rosenheim.DEU/19.08 & $\begin{array}{l}\text { Molecular: Switzerland } \\
\text { (MVs/Lucerne.CHE/46.06) }\end{array}$ & {$[16]$} \\
\hline \multicolumn{5}{|l|}{2009} \\
\hline $\begin{array}{l}\text { Hamburg } \\
(n=212)\end{array}$ & D4 & MVs/Hamburg.DEU/03.09 & $\begin{array}{l}\text { Molecular: United Kingdom } \\
\text { (MVs/Enfield.GBR/14.07) } \\
\text { Epidemiologic: Exported to } \\
\text { Bulgaria (MVs/Shumen. } \\
\text { BGR/15.09/1) }\end{array}$ & {$[17]$} \\
\hline $\begin{array}{l}\text { Lower Saxony } \\
(n=72)\end{array}$ & D4 & MVs/Hamburg.DEU/03.09 & $\begin{array}{l}\text { Molecular: United Kingdom } \\
\text { (MVs/Enfield.GBR/14.07) }\end{array}$ & \\
\hline $\begin{array}{l}\text { North Rhine-Westphalia } \\
(n=76)\end{array}$ & D4 & MVi/Duisburg.DEU/10.09 & & \\
\hline $\begin{array}{l}\text { Baden-Wurttemberg } \\
(n=67)\end{array}$ & D4 & MVs/Ravensburg.DEU/17.09 & & \\
\hline \multicolumn{5}{|l|}{2010} \\
\hline Berlin ( $n=69)$ & D8 & & $\begin{array}{l}\text { Epidemiologic: Travel } \\
\text { from India }\end{array}$ & [18] \\
\hline
\end{tabular}

NOTE. ${ }^{a}$ Number of cases by year and federal state according to electronic reporting system; the number may differ from the actual number of cases involved in the outbreak, because not all reported cases are genotyped or epidemiologically linked and genotype results are not always linked to reported case. MV, measles virus.

* All isolated viruses as indicated in the Measles Nucleotide surveillance database (MeaNS); available at http://www.who-measles.org/Public/Web_Front/about_db.php; accessed 7 March 2011. 
Table 3. Vaccination Status for Measles-Containing Vaccine (MCV) by Age in Participants of the State Vaccination Campaign, North Rhine-Westphalia, Germany, 2007-2008

Age, years

$\begin{array}{lcccccccccccc}\text { MCV vaccination status } & 10 & 11 & 12 & 13 & 14 & 15 & 16 & 17 & 18 & 19 & 20 & 21 \\ \text { Not vaccinated, \% } & 4.1 & 3.6 & 4.2 & 5.1 & 5.5 & 5.9 & 6.6 & 8.6 & 11.5 & 15.8 & 19.0 & 18.8 \% \\ \text { Vaccinated with only 1 dose, \% } & 7.6 & 9.2 & 10.5 & 11.7 & 11.6 & 12.0 & 13.7 & 14.3 & 15.2 & 16.1 & 21.2 & 25.0 \\ \text { Vaccinated with 2 doses, \% } & 88.4 & 87.2 & 85.2 & 83.2 & 82.0 & 82.1 & 79.7 & 77.1 & 73.3 & 68.1 & 59.8 & 56.2\end{array}$


Figure 1. Number of measles cases by quarter and federal states with highest incidences (cases/100,000 population) in the respective years due to outbreaks in Germany, 2001-2010. Roman numerals with years indicate quarters. BE, Berlin; BW, Baden-Wurttemberg; BY, Bavaria; HB, Bremen; HE, Hessen; HH, Hamburg; NI, Lower Saxony; NW, North Rhine-Westphalia; RP, Rhineland-Palatinate; SH, Schleswig-Holstein.

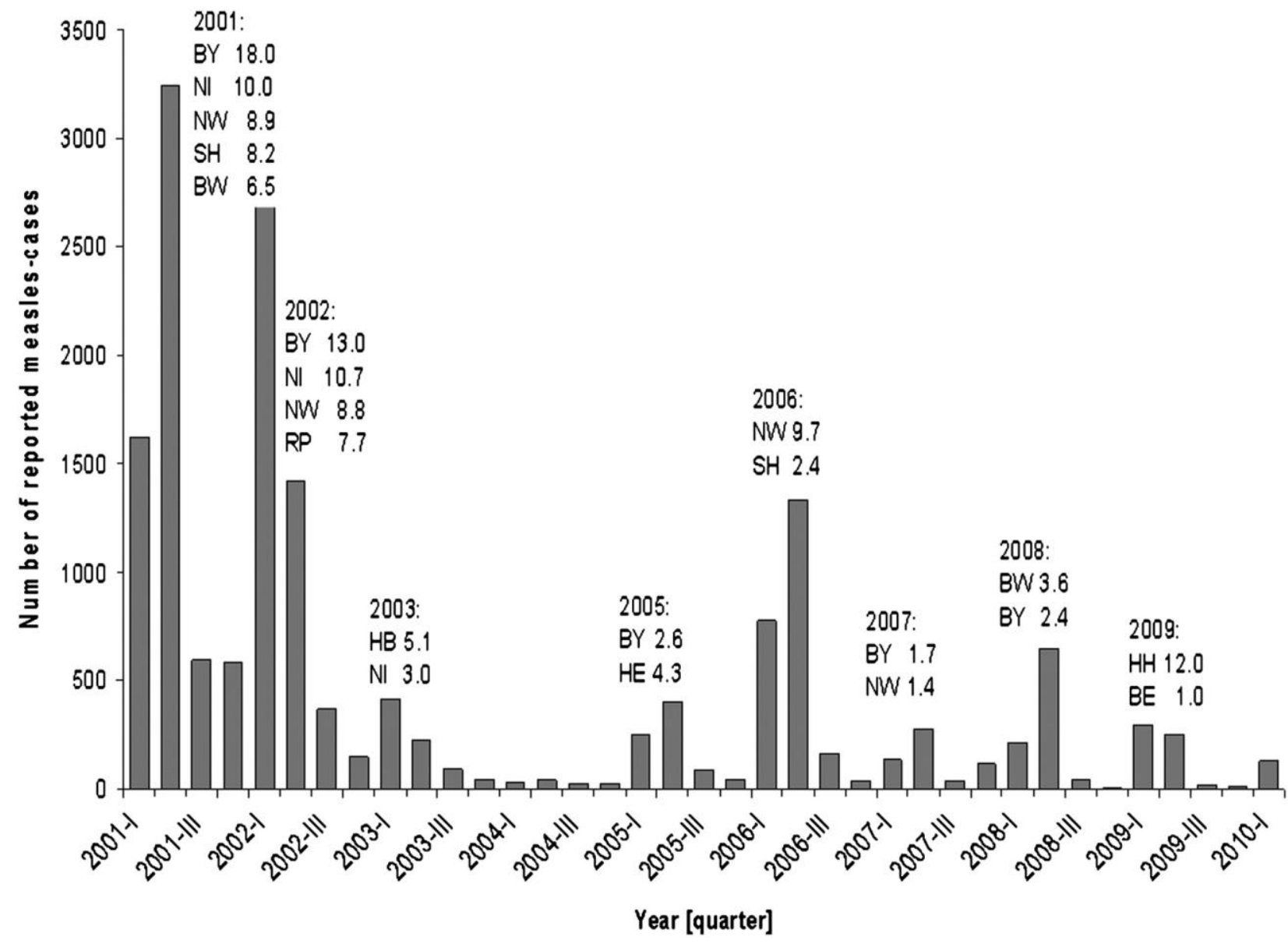

Figure 2. Median age-specific measles incidence in Germany in 2003-2005 compared with 2007-

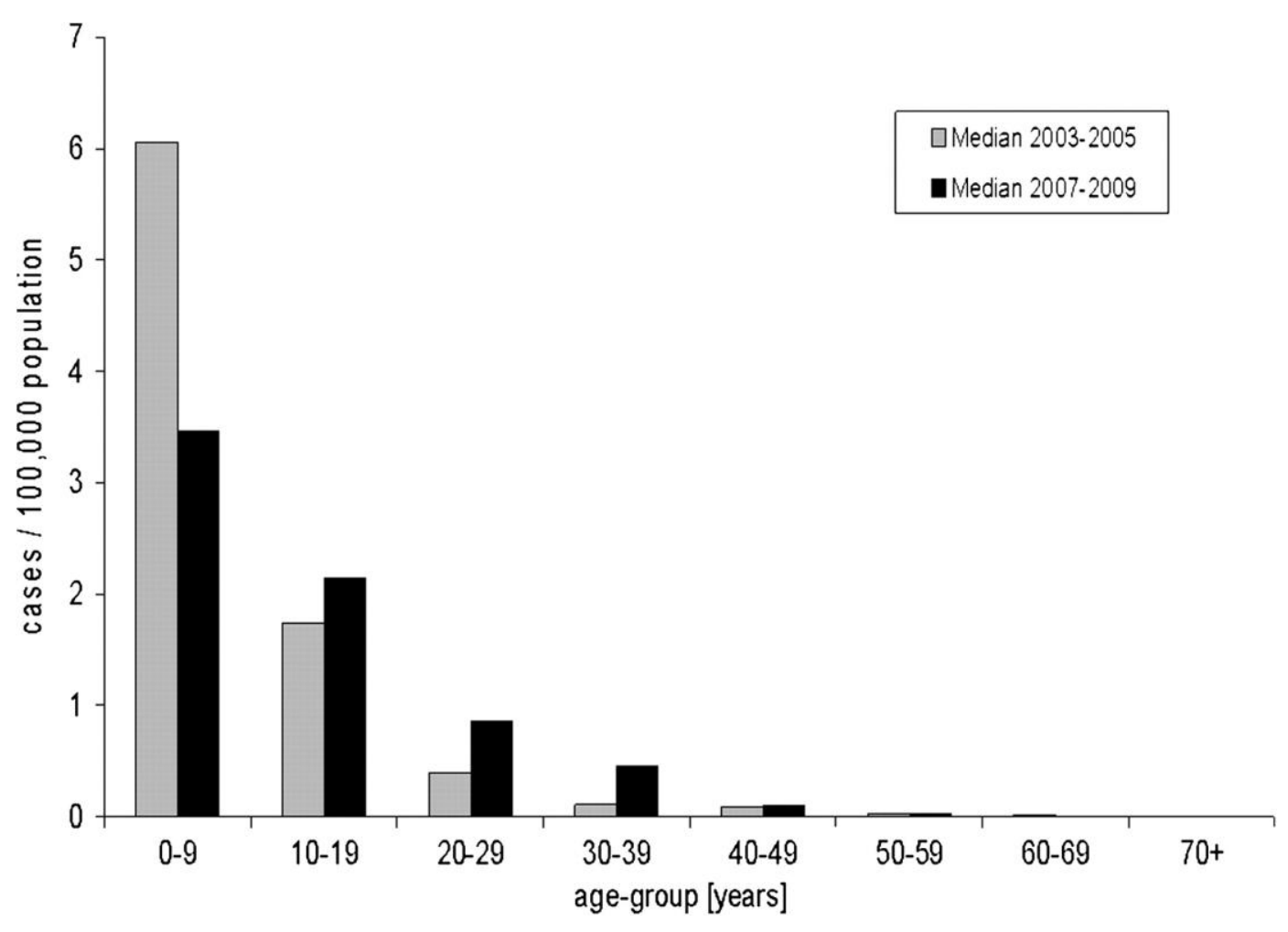

2009. 
Figure 3. Coverage with 1 or 2 doses of measles vaccine in old and new federal states (OFS and NFS) of Germany, assessed at school entry examination (at 4-6 years of age) in 1998-2008.

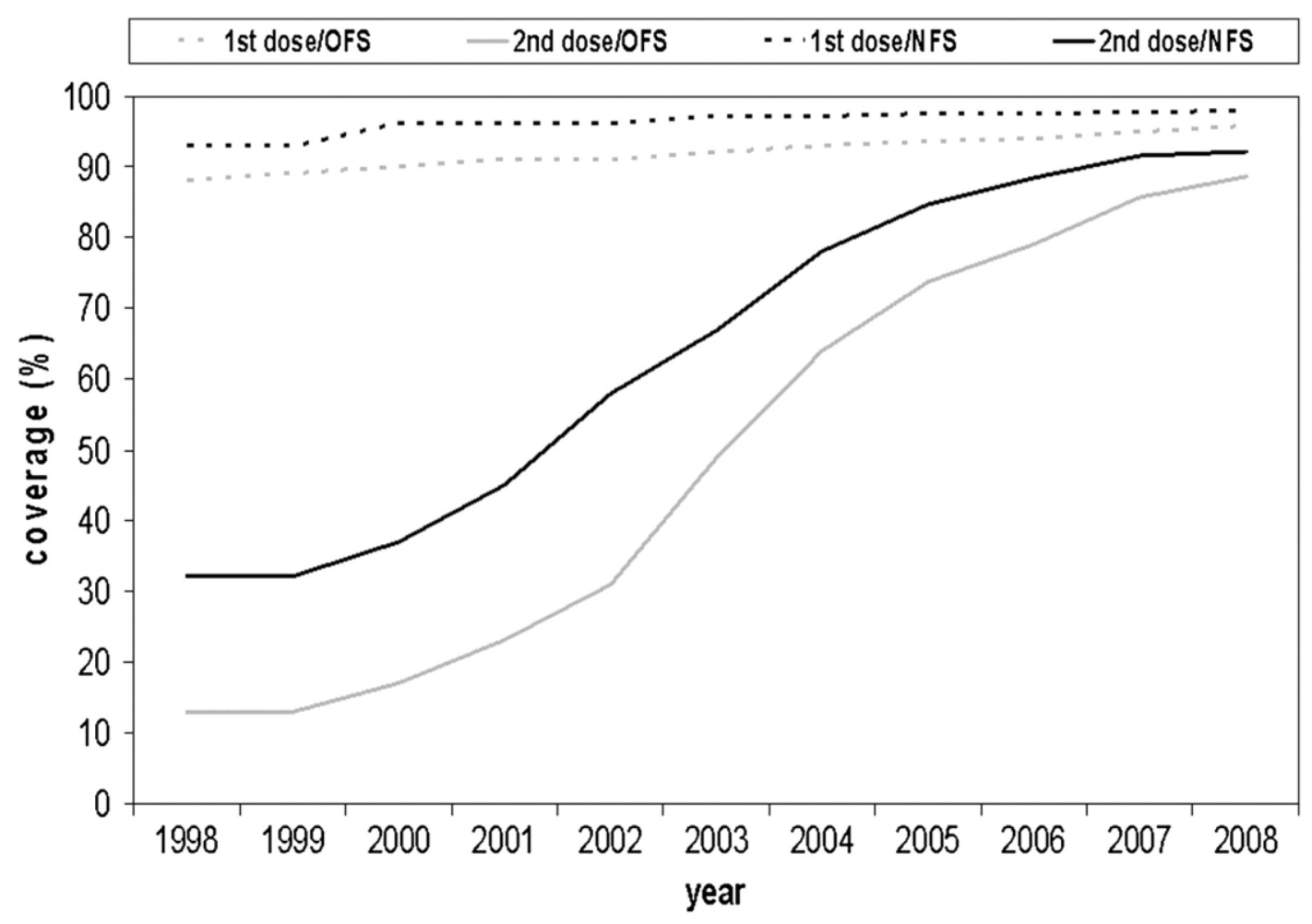

